\title{
Efficacy and safety of tiotropium bromide combined with budesonide/formoterol in the treatment of moderate to severe chronic obstructive pulmonary disease
}

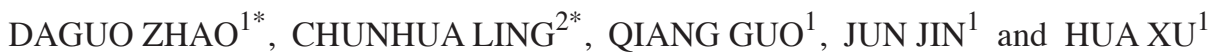 \\ Departments of ${ }^{1}$ Critical Care Medicine and ${ }^{2}$ Respiratory Medicine, \\ The First Affiliated Hospital of Soochow University, Suzhou, Jiangsu 215006, P.R. China
}

Received January 26, 2018; Accepted July 20, 2018

DOI: $10.3892 /$ etm.2018.6773

\begin{abstract}
With the increase of environmental pollution, chronic obstructive pulmonary disease (COPD) has become a serious health threat. In the present study, the efficacy and safety of inhalation therapy of tiotropium bromide combined with budesonide/formoterol were assessed in 180 patients with moderate to severe COPD (clinical trial registry no. ChiCTR1800017584). Patients were treated by inhalation of budesonide/formoterol (control group) or inhalation of tiotropium bromide combined with budesonide/formoterol (intervention group). The results indicated that after the treatment, the forced expiratory volume in $1 \mathrm{sec}$, the modified Medical Research Council scale, the 6-min walking distance and the St. George's Respiratory Questionnaire scores for quality of life were significantly improved in the two groups, while the improvements in the intervention group were more significant (all $\mathrm{P}<0.05$ ). There was no significant difference in body mass indices between the two groups during the course of the treatment $(\mathrm{P}=0.302)$. The difference in the risk of an acute exacerbation between the two groups was also not significant $(\mathrm{P}=0.238)$. The median time to the first acute exacerbation from the start of treatment in the intervention group (53 days; $25 \%$ quartile, 50 days; $75 \%$ quartile, 62 days) was significantly
\end{abstract}

Correspondence to: Mr. Hua Xu, Department of Critical Care Medicine, The First Affiliated Hospital of Soochow University, 899 Pinghai Road, Suzhou, Jiangsu 215006, P.R. China

E-mail: xuhua9056@163.com

*Contributed equally

Abbreviations: COPD, chronic obstructive pulmonary disease; $\mathrm{FEV}_{1}$, forced expiratory volume in 1 second; $\mathrm{FVC}$, forced vital capacity; $\mathrm{FEV}_{1} \%$ pred, $\mathrm{FEV}_{1}$ as percentage of predicted value; $\mathrm{BMI}$, body mass index; mMRC, modified Medical Research Council; 6MWT, six-minute walking test; SGRQ, St. George's Respiratory Questionnaire

Key words: chronic obstructive pulmonary disease, tiotropium bromide, efficacy, safety, budesonide, formoterol longer than that in the control group (37 days; $25 \%$ quartile, 23 days; 75\% quartile, 39 days; $\mathrm{P}=0.042$ ). The adverse reaction rates in the intervention and control groups were 14.4 and $10.0 \%$, respectively, without any significant difference. In conclusion, inhalation treatment of tiotropium bromide combined with budesonide/formoterol significantly improves pulmonary function, exercise capacity and quality of life of patients with COPD compared with budesonide/formoterol inhalation alone, while the effect of reducing the acute attack risk requires further evaluation.

\section{Introduction}

With the continuous progression of aging, severe air pollution and high smoking rate, chronic obstructive pulmonary disease (COPD) has become a serious health threat in China. In 2013, the prevalence rate of COPD in people $>40$ years was $7.3 \%$, making it a leading cause of disability, and it seriously affects the quality of life of affected patients $(1,2)$. As a chronic lung disease, COPD comprises an incompletely reversible airflow limitation and develops progressively. Therefore, the major purpose of treatment is to relieve symptoms, reduce exacerbation, and improve lung function and quality of life. The commonly used medications for COPD include inhaled glucocorticoids, methylxanthines and bronchodilators (including cholinolytic agents and $\beta_{2}$ receptor agonists); at present, multiple COPD treatment guidelines recommend combined application of different types of bronchodilators or application of bronchodilators combined with inhaled glucocorticoids $(3,4)$.

Tiotropium bromide is a long-acting cholinolytic bronchodilator. Studies have indicated that tiotropium alone improves lung function and quality of life, and reduces the risk of acute attack; in addition, long-term inhalation of tiotropium bromide and salmeterol/fluticasone reduces the frequency of acute exacerbation of COPD and the risk of mortality, and improves the health-associated quality of life of affected patients $(5,6)$. However, the combined application of tiotropium bromide and $\beta_{2}$ receptor agonist bronchodilators or glucocorticoids remains controversial (7). Previous studies assessing inhalation therapy of tiotropium bromide combined with budesonide/formoterol have provided conflicting results $(8,9)$. Therefore, the present 
study aimed to further evaluate the efficacy and safety of tiotropium bromide combined with budesonide/formoterol in patients with moderate to severe COPD.

\section{Patients and methods}

Subjects. The present study was approved by the Ethics Committee of the First Affiliated Hospital of Soochow University (Suzhou, China). A total of 180 patients with moderate to severe COPD (groups B and C) in the stable phase treated at the First Affiliated Hospital of Soochow University from January 2014 to December 2015 were included. Demographic characteristics including age and sex were collected at the beginning of the study.

The inclusion criteria were as follows: Patients aged $>18$ years; patients who were diagnosed with group B and C COPD in accordance with the Guidelines for the Diagnosis and Treatment of Chronic Obstructive Pulmonary Disease (revised edition from 2013), published by the COPD Group of the Chinese Thoracic Society (3); patients who received inhalation therapy; patients who did not receive any cholinolytic drugs within 4 weeks; patients who did not suffer from any acute attack and did not receive any antibiotic therapy for 4 weeks; patients who had not received any systemic glucocorticoid therapy in the past two months; patients who provided written informed consent. The exclusion criteria were as follows: Patients who were allergic to tiotropium bromide, budesonide/formoterol inhalation or any other inhaled ingredients; patients with diseases rendering them unsuitable for inhalation therapy, including bronchial lung cancer, dilatation and interstitial lung diseases; patients suffering from other systemic diseases, including heart, liver, kidney, hematopoietic and nervous system diseases, glaucoma or severe prostatic hyperplasia; patients who were considered unsuitable for participating in the drug trial by the clinicians.

Grouping and treatment. A total of 180 cases with moderate to severe COPD were randomly divided into a control group (positive drug controls) and an intervention group by using a random number table, with 90 cases in each group. Each of the two groups went through a 1-week washout period, after which they received treatment for 6 months. The control group received budesonide/formoterol (160/4.5 $\mu \mathrm{g} ; 1$ suction/time, 2 times/day; Symbicort Turbuhaler; AstraZeneca, Cambridge, UK). Based on the control group treatment, patients in the intervention group received additional treatment of tiotropium bromide (1.8 $\mu \mathrm{g}$ inhaled once a day before bed; Spiriva; C.H. Boehringer Sohn AG \& Ko. KG, Ingelheim, Germany). During the study period, patients were provided with salbutamol inhalation on demand; antibiotics and antiviral drugs were used in specific cases if required.

Evaluation indices. The following indices were determined prior to treatment and after treatment for 3 and 6 months.

Lung function indices included the forced expiratory volume in 1 second $\left(\mathrm{FEV}_{1}\right)$, the $\mathrm{FEV}_{1}$ /forced vital capacity (FVC) and the $\mathrm{FEV}_{1}$ as a percentage of the predicted value (FEV, \%pred).

Weight and height were measured for calculating the body mass index (BMI).
The dyspnea score was evaluated using the modified Medical Research Council (mMRC) scale (10). The scale included four grades, with a higher score indicating more serious dyspnea, ranging from 0 points-no breathing difficulties except during strenuous exercise, to 4 points-dyspnea when leaving the room, dressing or other light activities. The degrees of dyspnea were scored according to the patients' own description.

The six-minute walking test (6MWT) was performed by measuring the longest distance that patients were able to walk within 6 min while they were walking back and forth on corridor of $20 \mathrm{~m}$ in length (11). The test was performed twice with an interval time of at $\geq 2 \mathrm{~h}$ and the optimum value was recorded. This test was performed to assess the exercise tolerance of patients.

Health-associated quality of life was assessed using St. George's Respiratory Questionnaire (SGRQ) (12). SGRQ consisted of 50 items and three parts, assessing the influence of symptoms, ability to perform activities and disease on daily life, with a total score of 100 points. The score was negatively correlated with the health state. On the day of the pulmonary function test, the questionnaires were completed by the patients independently, and the researchers checked whether there was any omission.

During follow-up period, occurrence and time of acute exacerbation were recorded for the evaluation of acute attack risk and occurrence of mortality and adverse reactions were recorded for the evaluation of safety.

Statistical analysis. All data were processed using SPSS 20.0 (IBM Corp., Armonk, NY, USA). The measurement data were expressed as the mean \pm standard deviation, and the difference in baseline measurement data between the two groups were compared with an independent-samples t-test. The difference test of categorical variables between the two groups was performed by using the two-tailed $\chi^{2}$ test or Fisher's exact probability test.

Comparisons of lung function, BMI, mMRC, 6MWT and SGRQ scores at different time-points, as well as differences in treatment effects of the two treatment methods at different time-points (interaction of treatment and time), were analyzed by repeated-measures analysis of variance (ANOVA). If the overall difference between the two groups in the repeated-measures ANOVA was significant, Bonferroni's post-hoc test (significance level set at $0.05 / 3=0.0167$ ) was performed for the comparison of detection values or score at the same time-point. The risk of acute exacerbation since the start of treatment was compared between the groups by Kaplan-Meier survival analysis, with significant differences determined using the log-rank test. The days between first onset from the start of treatment exhibited a skewed distribution; therefore, the data were expressed as median (25 and 75\% quartile) and the Mann-Whitney U-test was used for assessment of statistically significant differences. The study was analyzed in line with the Intent-To-Treat principle; for subjects that dropped out during the study, analysis was performed according to their last available data. The level of statistical significance was set as bilateral $\alpha=0.05$ (except for Bonferroni's post-hoc test).

\section{Results}

General information. During the study period, 1 patient in the intervention group and 1 in control group dropped out due to 
Table I. General information on the patients in the two groups.

\begin{tabular}{|c|c|c|c|c|}
\hline Characteristic & Intervention group $(\mathrm{n}=90)$ & Control group $(n=90)$ & $\chi^{2 / t}$ & P-value \\
\hline Age (years) & $56.7 \pm 8.2$ & $54.8 \pm 7.9$ & 1.583 & 0.115 \\
\hline Sex & & & 1.693 & 0.193 \\
\hline Male & $67(74.4)$ & $59(65.6)$ & & \\
\hline Female & $23(25.6)$ & $31(34.4)$ & & \\
\hline Smoking history & & & 2.025 & 0.155 \\
\hline No & $13(14.4)$ & $7(7.8)$ & & \\
\hline Yes & $77(85.6)$ & $83(92.2)$ & & \\
\hline Course of disease (years) & $11.6 \pm 5.7$ & $10.3 \pm 5.1$ & 1.612 & 0.109 \\
\hline COPD degree & & & 1.105 & 0.293 \\
\hline B & $47(52.2)$ & $54(60.6)$ & & \\
\hline $\mathrm{C}$ & $43(47.8)$ & $36(40.0)$ & & \\
\hline
\end{tabular}

Values are expressed as $\mathrm{n}(\%)$ or the mean \pm standard deviation. COPD, chronic obstructive pulmonary disease.

Table II. Pulmonary function evaluation in the two groups.

\begin{tabular}{|c|c|c|c|c|c|c|c|c|c|}
\hline \multirow{2}{*}{$\begin{array}{l}\text { Pulmonary } \\
\text { function parameter }\end{array}$} & \multirow{2}{*}{$\begin{array}{l}\text { Prior to } \\
\text { treatment }\end{array}$} & \multirow{2}{*}{$\begin{array}{l}\text { After } 3 \\
\text { months } \\
\text { treatment }\end{array}$} & \multirow{2}{*}{$\begin{array}{c}\text { After } 6 \\
\text { months } \\
\text { treatment }\end{array}$} & \multicolumn{2}{|c|}{$\begin{array}{c}\text { Difference } \\
\text { between groups }\end{array}$} & \multicolumn{2}{|c|}{ Time effect } & \multicolumn{2}{|c|}{$\begin{array}{l}\text { Group/time } \\
\text { interaction }^{\mathrm{a}}\end{array}$} \\
\hline & & & & $\mathrm{F}$ & P-value & $\mathrm{F}$ & P-value & $\mathrm{F}$ & P-value \\
\hline $\mathrm{FEV}_{1}(1)$ & & & & 4.783 & 0.030 & 3.417 & 0.034 & 3.253 & 0.040 \\
\hline Intervention group & $1.10 \pm 0.35$ & $1.40 \pm 0.42$ & $1.46 \pm 0.45$ & & & & & & \\
\hline Control group & $1.14 \pm 0.39$ & $1.25 \pm 0.40$ & $1.25 \pm 0.41$ & & & & & & \\
\hline $\mathrm{t}, \mathrm{P}$-value ${ }^{\mathrm{b}}$ & $0.724,0.470$ & $2.453,0.015$ & $3.272,0.001$ & & & & & & \\
\hline $\mathrm{FEV}_{1} / \mathrm{FVC}(\%)$ & & & & 4.209 & 0.042 & 3.672 & 0.026 & 2.342 & 0.098 \\
\hline Intervention group & $54.34 \pm 9.30$ & $58.52 \pm 9.79$ & $62.01 \pm 9.10$ & & & & & & \\
\hline Control group & $53.27 \pm 8.67$ & $56.02 \pm 8.36$ & $58.28 \pm 8.71$ & & & & & & \\
\hline t, P-value ${ }^{b}$ & $0.798,0.426$ & $1.842,0.067$ & $2.809,0.006$ & & & & & & \\
\hline $\mathrm{FEV}_{1} \%$ pred & & & & 4.357 & 0.038 & 3.944 & 0.020 & 0.571 & 0.565 \\
\hline Intervention group & $52.32 \pm 6.67$ & $55.89 \pm 7.08$ & $59.02 \pm 7.24$ & & & & & & \\
\hline Control group & $52.17 \pm 7.67$ & $53.75 \pm 7.15$ & $55.93 \pm 7.45$ & & & & & & \\
\hline $\mathrm{t}, \mathrm{P}$-value ${ }^{\mathrm{b}}$ & $0.140,0.889$ & $2.017,0.045$ & $2.821,0.005$ & & & & & & \\
\hline
\end{tabular}

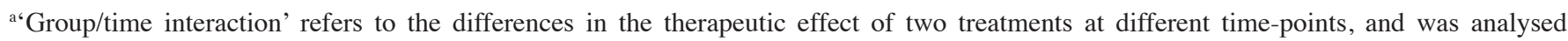
by repeated-measures analysis of variance. 'Difference between two groups determined by Bonferroni's post-hoc test (significance level, $0.05 / 3=0.0167$ ). Values are expressed as the mean \pm standard deviation. $\mathrm{FEV}_{1}$, forced expiratory volume in 1 second; FVC, forced vital capacity; $\mathrm{FEV}_{1} \%$ pred, $\mathrm{FEV}_{1}$ as percentage of predicted value.

of adverse reactions. The baseline and clinical characteristics of the patients in the two groups are presented in Table I. There was no significant difference in age, sex, smoking history, course of disease and degree of COPD between the two groups, indicating similar baseline and clinical data.

Co-treatment with tiotropium bromide significantly enhances the improvement of lung function in COPD patients receiving budesonide/formoterol. Table II presents the comparison of lung function between the two groups prior to treatment, and after treatment for 3 and 6 months. There was no significant difference in pulmonary function indices between the two groups prior to treatment. Repeated-measures ANOVA indicated that over the treatment time, the $\mathrm{FEV}_{1}, \mathrm{FEV}_{1} / \mathrm{FVC}(\%)$ and $\mathrm{FEV}_{1} \%$ pred exhibited time-dependent increases in the groups $(\mathrm{P}=0.034, \mathrm{P}=0.026$ and $\mathrm{P}=0.020$, respectively). Over the entire treatment duration, the differences in the above three indicators between the two groups were also significant $(\mathrm{P}=0.030, \mathrm{P}=0.042$ and $\mathrm{P}=0.038$, respectively), and the improvement of lung function in the intervention group was significantly better than that in the control group. The FEV in the intervention group was significantly higher than that in the control group after treatment for 3 months $(\mathrm{P}=0.015)$ and 6 months $(\mathrm{P}=0.001)$; furthermore, at 6 months, the $\mathrm{FEV}_{1} / \mathrm{FVC}$ 
Table III. Comparison of BMI, mMRC, 6MWT and SGRQ scores in the two groups.

\begin{tabular}{|c|c|c|c|c|c|c|c|c|c|}
\hline \multirow[b]{2}{*}{ Score } & \multirow{2}{*}{$\begin{array}{l}\text { Prior to } \\
\text { treatment }\end{array}$} & \multirow{2}{*}{$\begin{array}{c}\text { After } 3 \\
\text { months } \\
\text { treatment }\end{array}$} & \multirow{2}{*}{$\begin{array}{c}\text { After } 6 \\
\text { months } \\
\text { treatment }\end{array}$} & \multicolumn{2}{|c|}{$\begin{array}{c}\text { Difference } \\
\text { between groups }\end{array}$} & \multicolumn{2}{|c|}{ Time effect } & \multicolumn{2}{|c|}{$\begin{array}{l}\text { Group/time } \\
\text { interaction }^{\text {a }}\end{array}$} \\
\hline & & & & $\mathrm{F}$ & P-value & $\mathrm{F}$ & P-value & $\mathrm{F}$ & P-value \\
\hline BMI $\left(\mathrm{kg} / \mathrm{m}^{2}\right)$ & & & & 1.072 & 0.302 & 3.142 & 0.044 & 1.282 & 0.279 \\
\hline Intervention group & $21.2 \pm 2.7$ & $21.9 \pm 2.8$ & $22.4 \pm 3.2$ & & & & & & \\
\hline Control group & $20.9 \pm 2.6$ & $21.6 \pm 3.0$ & $22.0 \pm 2.9$ & & & & & & \\
\hline mMRC score & & & & 4.233 & 0.041 & 4.110 & 0.017 & 0.469 & 0.626 \\
\hline Intervention group & $3.02 \pm 0.46$ & $2.45 \pm 0.31$ & $1.53 \pm 0.26$ & & & & & & \\
\hline Control group & $3.05 \pm 0.53$ & $2.67 \pm 0.36$ & $1.85 \pm 0.29$ & & & & & & \\
\hline $\mathrm{t}, \mathrm{P}-$ value $^{\mathrm{b}}$ & $0.406,0.686$ & $4.393,0.001$ & $7.794,0.001$ & & & & & & \\
\hline 6MWT (m) & & & & 4.091 & 0.044 & 3.926 & 0.021 & 2.149 & 0.118 \\
\hline Intervention group & $283.9 \pm 42.65$ & $322.8 \pm 48.89$ & $331.92 \pm 49.87$ & & & & & & \\
\hline Control group & $279.5 \pm 40.09$ & $309.77 \pm 47.15$ & $314.23 \pm 47.29$ & & & & & & \\
\hline $\mathrm{t}, \mathrm{P}$-value ${ }^{\mathrm{b}}$ & $0.713,0.477$ & $1.820,0.070$ & $2.442,0.016$ & & & & & & \\
\hline SGRQ score & & & & 4.561 & 0.034 & 3.769 & 0.024 & 1.785 & 0.169 \\
\hline Intervention group & $59.47 \pm 7.15$ & $54.56 \pm 6.64$ & $53.32 \pm 5.94$ & & & & & & \\
\hline Control group & $58.64 \pm 6.41$ & $50.21 \pm 6.17$ & $48.28 \pm 6.05$ & & & & & & \\
\hline$t, P$-value ${ }^{b}$ & $0.820,0.413$ & $4.553,<0.001$ & $5.639,<0.001$ & & & & & & \\
\hline
\end{tabular}

${ }^{a}$ Group/time interaction' refers to the differences in the therapeutic effect of two treatments at different time-points, and was analysed by repeated-measures analysis of variance. 'Difference between two groups determined by Bonferroni's post-hoc test (significance level, $0.05 / 3=0.0167)$. Values are expressed as the mean \pm standard deviation. BMI, body mass index; mMRC, modified Medical Research Council; 6MWT, six-minute walking test; SGRQ, St. George's Respiratory Questionnaire.

$(\%, \mathrm{P}=0.006)$ and $\mathrm{FEV}_{1} \%$ pred $(\mathrm{P}=0.005)$ in the intervention group were significantly higher than those in the control group.

Comparison of BMI, mMRC, 6MWT and SGRQ scores between the two groups during treatment. Similar to the results regarding pulmonary function, the $\mathrm{BMI}(\mathrm{P}=0.044)$, mMRC score $(\mathrm{P}=0.017), 6 \mathrm{MWT}$ score $(\mathrm{P}=0.021)$ and SGRQ score $(\mathrm{P}=0.024)$ in the two groups improved significantly during treatment, suggesting that nutritional status, dyspnea, exercise endurance and quality of life in the two groups were significantly improved. The improvements of mMRC, 6MWT and SGRQ scores in the intervention group were significantly better than those in the control group $(\mathrm{P}=0.041$, $\mathrm{P}=0.044$ and $\mathrm{P}=0.034$, respectively), but the difference in the BMI between the two groups was not statistically significant ( $\mathrm{P}=0.302$; Table III).

Effect of treatment on acute exacerbations. During the study, acute exacerbation in the intervention group and the control group occurred in $5(5.6 \%)$ and 9 cases (10\%), respectively. Survival analysis indicated that the difference in the risk of acute exacerbation between the two groups was not significant (log-rank test, $\mathrm{P}=0.238$; Fig. 1). However, the median time to the first acute exacerbation from the start of the treatment in the intervention group was 53 days (25\% quartile, 50 days; $75 \%$ quartile, 62 days), which was significantly longer than that in the control group (median, 37 days; $25 \%$ quartile, 23 days; 75\% quartile, 39 days; Mann-Whitney U test, $\mathrm{P}=0.042$ ) (Fig. 2).

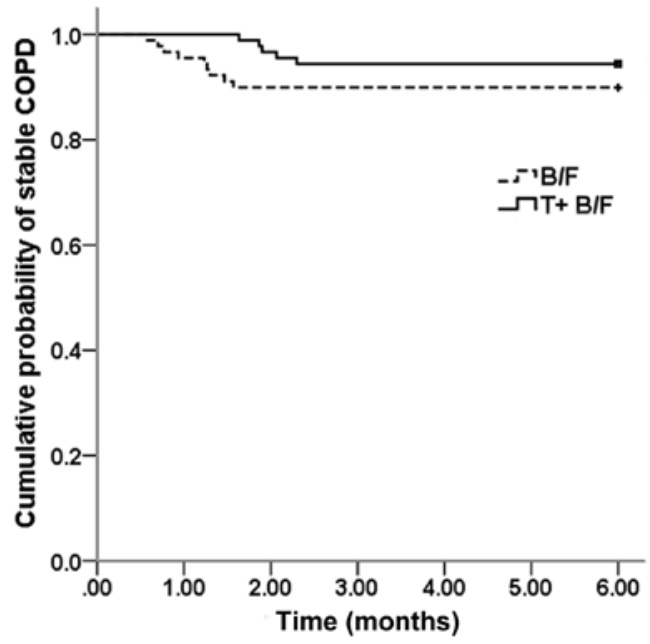

Figure 1. Risk of acute attack in the two groups. There was no significant difference in the risk of acute exacerbation between the two groups during the study ( $\log$ rank test $\mathrm{P}=0.238$ ). COPD, chronic obstructive pulmonary disease.

Adverse reactions. The incidence of adverse reactions in the intervention group and control group was 14.4 and $10.0 \%$, respectively, and there was no significant difference in the rate of adverse reactions between the two groups. The major adverse reactions included dry mouth, pharynx discomfort, oral ulcer, dysuria and sinus arrhythmia (Table IV). Furthermore, 1 patient in the intervention group and 1 patient in the control group dropped out due to their perceived lack of a therapeutic effect. No mortalities occurred during study. 
Table IV. Adverse reactions in the two groups.

\begin{tabular}{lccr}
\hline Adverse reactions & Intervention $(\mathrm{n}=90)$ & Control group $(\mathrm{n}=90)$ & $\chi^{2}$ \\
\hline No & $77(85.6)$ & $81(90.0)$ & 0.829 \\
Yes & $13(14.4)$ & $9(10.0)$ & 0.363 \\
Dry mouth & $5(5.6)$ & $3(3.3)$ & $0.720^{\mathrm{a}}$ \\
Pharynx discomfort & $2(2.2)$ & $2(2.2)$ & $1.000^{\mathrm{a}}$ \\
Oral ulcer & $2(2.2)$ & $2(2.2)$ & $1.000^{\mathrm{a}}$ \\
Dysuria & $2(2.2)$ & $2(2.2)$ & $1.000^{\mathrm{a}}$ \\
Sinus tachycardia & $2(2.2)$ & $0(0.0)$ & $0.497^{\mathrm{a}}$
\end{tabular}

${ }^{a}$ Fisher's exact probability test. Values are expressed as n (\%).

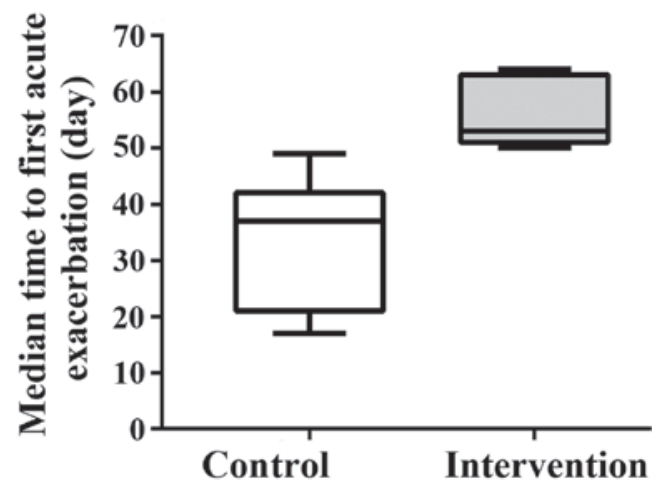

Figure 2. Median time to the first exacerbation since the start of the treatment in the two groups. The median time to the first exacerbation in the intervention group (53 days; $25 \%$ quartile, 50 days; $75 \%$ quartile, 62 days) was significantly longer than that in the control group (37 days; $25 \%$ quartile, 23 days; $75 \%$ quartile, 39 days; $\mathrm{P}=0.042$ ).

\section{Discussion}

Acute exacerbation of COPD is mainly caused by airway obstruction, which is triggered by chronic inflammation of the airways, lung parenchyma and blood vessels, resulting in a limitation of lung function and serious impairment of the quality of life of affected patients. However, a study has indicated that the level of inflammatory markers in patients with COPD in the stable phase remains higher than that in healthy individuals, suggesting that inflammation prevails in the stable phase (13). Therefore, the major treatment target in the stable phase COPD is to control inflammation, relieve symptoms, improve exercise tolerance and the health status, as well as to prevent acute exacerbation (14).

Tiotropium bromide is a novel cholinolytic bronchodilator, which dilates the bronchus through competing with acetylcholine and combining with the $\mathrm{M}_{1}$ and $\mathrm{M}_{3}$ receptors; the dissociation time with the $\mathrm{M}_{3}$ receptor is up to $35 \mathrm{~h}$, resulting in long-lasting anti-cholinergic effects: After one administration, the dilation of the bronchus is maintained for $\geq 24 \mathrm{~h}$. In addition, through competitive inhibition of the combination of acetylcholine and the $\mathrm{M}$ receptor, it suppresses inflammation and airway remodeling $(15,16)$. The 4 -year large-scale prospective randomized double-blinded placebo-controlled UPLIFT trial indicated that compared with placebo, tiotropium bromide continuously and effectively improved the lung function and quality of life of COPD patients, and reduced the risk of exacerbation and all-cause mortality; while it failed to improve the downward trend of the $\mathrm{FEV}_{1}$, subgroup analysis indicated that the decrease rate of $\mathrm{FEV}_{1}$ in young patients was significantly improved $(17,18)$. A systematic evaluation, which compared tiotropium bromide with placebo, further confirmed these results (19). In addition, a study also demonstrated that tiotropium bromide and budesonide/formoterol had similar effects in the prevention of acute exacerbation (20).

Formoterol, as a highly selective long-acting $\beta_{2}$ receptor agonist, improves airway obstruction and pulmonary function of COPD patients, relieves symptoms and increases the intake of glucocorticoid receptor/liposome complexes (21). Formoterol and tiotropium bromide further increase the bronchiectatic effect, but with a different mechanism (22). Furthermore, budesonide, an efficient local anti-inflammatory glucocorticoid, inhibits the production of inflammatory factors and the activity of inflammatory cells from multiple links, so as to improve airway inflammation, prevent airway remodeling and increase the number of cell membrane $\beta_{2}$ receptor. Theoretically, tiotropium bromide, budesonide and formoterol should have synergistic effects (23). A study has indicated that compared with tiotropium bromide alone, the combination of tiotropium bromide and budesonide/formoterol more effectively improves pulmonary function, $\mathrm{mMRC}$ and $6 \mathrm{MWT}$, reduces acute exacerbation and is also preferable due to its cost-effectiveness (24). Systematic reviews have indicated that the combination of the above three drugs obviously decreased the acute exacerbation of COPD, but their evaluation indices did not include lung function, nutritional status and exercise capacity, which ware of great significance in the evaluation of COPD; furthermore, the analysis suggested that budesonide and formoterol may be associated with an increased risk of pneumonia $(25,26)$. Thus, the efficacy and safety of the combination of the three drugs should be further evaluated.

The results of the present study demonstrated that the lung function, mMRC, 6MWT and SGRQ scores were significantly improved in the two groups after treatment, but the improvements in the intervention group were more significant; however, the difference in the adverse reaction rates between the two groups was not significant. These results were similar to those of previous analogous studies, which 
indicated that compared with budesonide/formoterol alone, tiotropium bromide combined with budesonide/formoterol significantly improved indicators of COPD, including pulmonary function, quality of life and exercise capacity, but that adverse reactions were not significantly different from those in the budesonide/formoterol treatment group $(21,27)$.

Previous studies have demonstrated that tiotropium bromide combined with budesonide/formoterol significantly reduced the risk of acute exacerbation in patients with COPD $(28,29)$. In the present study, Kaplan-Meier analysis indicated that there was no significant difference in the risk of acute exacerbations between the two groups, which may be due to the patients' different state of COPD among the studies. In one study, COPD was complicated with respiratory failure in all subjects (29), while the subjects of the present study were patients with moderate to severe COPD, so the incidence of acute exacerbations in the short study period was relatively lower, and the difference in the risk of acute exacerbations between the two groups was not significant, which was similar to the results of another two studies on the combined application of tiotropium bromide with fluticasone/salmeterol $(5,30)$. However, in the present study, the time to the first acute exacerbation from the start of the treatment in the intervention group was significantly longer compared with that in the control group. Thus, further evaluation is required to elucidate whether the combination of tiotropium bromide and budesonide/formoterol has a better efficacy in reducing the risk of acute exacerbation compared with budesonide/formoterol alone. The nutritional status in each of the two groups was significantly improved when compared with that prior to treatment, but the difference between the two groups was not significant, which was similar to the result of another study (27); possible reasons for the insignificant difference between the groups may be the short study period and the small sample size. In addition, the improvement of the quality of life in the intervention group was significantly greater than that in the control group, but according to a meta-analysis, the difference in the improvement of the SGRQ score between COPD patients treated with tiotropium bromide combined with budesonide/formoterol and those with tiotropium bromide alone was not statistically significant (8).

Of note, the present study had various shortcomings, including a small sample size, short-term evaluation of the efficacy and safety, and unavoidable bias from researchers and patients, as they were not blinded to the treatments. Therefore, the efficacy and long-term safety of tiotropium bromide combined with budesonide/formoterol requires further assessment in a randomized double-blinded controlled trial with a larger sample size.

In conclusion, the present study comprehensively evaluated the efficacy of inhalation therapy of tiotropium bromide combined with budesonide/formoterol in patients with moderate to severe COPD from the aspects of lung function, nutritional status, degree of dyspnea and exercise capacity. It was demonstrated that the combination of tiotropium bromide and budesonide/formoterol is significantly more efficacious than budesonide/formoterol alone with regard to various endpoints, including the improvement of lung function.

\section{Acknowledgements}

Not applicable.

\section{Funding}

No funding was received.

\section{Availability of data and materials}

The analysed data sets generated during the study are available from the corresponding author on reasonable request.

\section{Authors' contributions}

DZ was the guarantor for integrity of the study and contributed to study concepts, experimental studies and data analysis. CL contributed to study design and statistical analysis. QG contributed to statistical analysis, provided intellectual content and revised the manuscript. HX contributed to the literature research, clinical studies and manuscript preparation. JJ contributed to manuscript review and data acquisition. The final version of the manuscript was read and approved by all authors.

\section{Ethics approval and consent to participate}

The present study was approved by the Ethics Committee of the First Affiliated Hospital of Soochow University. All patients provided informed consent.

\section{Patient consent for publication}

Not applicable.

\section{Competing interests}

The authors declare that they have no competing interests.

\section{References}

1. Yin P, Wang H, Vos T, Li Y, Liu S, Liu Y, Liu J, Wang L, Naghavi M, Murray CJ and Zhou M: A subnational analysis of mortality and prevalence of COPD in China From 1990 to 2013: Findings from the global burden of disease study 2013. Chest 150: 1269-1280, 2016

2. Guan WJ, Ran PX and Zhong NS: Prevention and management of COPD in China: Successes and major challenges. Lancet Respir Med 4: 428-430, 2016.

3. COPD Group of Chinese Thoracic Society: Guidelines for the diagnosis and treatment of chronic obstructive pulmonary disease (2013 revised edition). Chin J Tuberculosis Respiratory Dis: 4, 255-264, 2013 (In Chinese).

4. Tunks M and Miller D: Canadian Thoracic Society recommendations for management of chronic obstructive pulmonary disease-2008 update-highlights for primary care. Can Respir J 15: 219, 2008.

5. Jung KS, Park HY, Park SY, Kim SK, Kim YK, Shim JJ, Moon HS, Lee KH, Yoo JH, Lee SD, et al: Comparison of tiotropium plus fluticasone propionate/salmeterol with tiotropium in COPD: A randomized controlled study. Respir Med 106: 382-389, 2012.

6. Farne HA and Cates CJ: Long-acting beta2-agonist in addition to tiotropium versus either tiotropium or long-acting beta2-agonist alone for chronic obstructive pulmonary disease. Cochrane Database Syst Rev: CD008989, 2015. 
7. Hodder R: Tiotropium is superior to salmeterol in reducing frequency of exacerbations: But the effect of adding tiotropium to the combination of inhaled corticosteroid and long-acting $\beta(2)$-agonist remains unclear. Evid Based Med 17: 93-95, 2012.

8. Zeng LM, Yu XL, Zhang QH, Peng QM, Zhou ZJ and Han FD: The Efficacy and Safety of Tiotropium Plus Budesonide/Formoterol Compared with Tiotropium in Chinese Patients with Chronic Obstructive Pulmonary Disease: A Meta-analysis. Chin Zhong Guo Hu Xi Yu Wei Zhong Jian Hu Za Zhi 2: 119-126, 2016 (In Chinese).

9. Zhang WJ, Li H, Liu XH and Chen J: Study on the clinical efficacy of combined inhalation of budesonide/formoterol and tiotropium bromide in the treatment of moderate and severe COPD. Guide China Med 36: 148-149, 2013.

10. Mahler DA and Wells CK: Evaluation of clinical methods for rating dyspnea. Chest 93: 580-586, 1988.

11. ATS Committee on Proficiency Standards for Clinical Pulmonary Function Laboratories: ATS statement: Guidelines for the six-minute walk test. Am J Respir Crit Care Med 166 111-117, 2002.

12. Jones PW, Quirk FH, Baveystock CM and Littlejohns P: A self-complete measure of health status for chronic airflow limitation. The St. George's respiratory questionnaire. Am Rev Respir Dis 145: 1321-1327, 1992.

13. Kersul AL, Iglesias A, Rios A, Noguera A, Forteza A, Serra E, Agusti A and Cosio BG: Molecular mechanisms of inflammation during exacerbations of chronic obstructive pulmonary disease. Arch Bronconeumol 47: 176-183, 2011.

14. Chen YH and Wang C: Breif introduction of GOLD global strategy for diagnosis, treatment and prevention of chronic obstructive pulmonary disease (2015 revised edition). Zhong Guo Yi Xue Qian Yan Za Zhi: Dian Zi Ban 7 34-39, 2015 (In Chinese).

15. Bateman ED, Rennard S, Barnes PJ, Dicpinigaitis PV, Gosens R Gross NJ, Nadel JA, Pfeifer M, Racké K, Rabe KF, et al: Alternative mechanisms for tiotropium. Pulm Pharmacol Ther 22: 533-542, 2009.

16. Toumpanakis D, Loverdos K, Tzouda V, Vassilakopoulou V, Litsiou E, Magkou C, Karavana V, Pieper $M$ and Vassilakopoulos T: Tiotropium bromide exerts anti-inflammatory effects during resistive breathing, an experimental model of severe airway obstruction. Int J Chron Obstruct Pulmon Dis 12: 2207-2220, 2017.

17. Tashkin DP: Impact of tiotropium on the course of moderate-to-very severe chronic obstructive pulmonary disease: The UPLIFT trial. Expert Rev Respir Med 4: 279-289, 2010.

18. Morice AH, Celli B, Kesten S, Lystig T, Tashkin D and Decramer M: COPD in young patients: A pre-specified analysis of the four-year trial of tiotropium (UPLIFT). Respir Med 104: 1659-1667, 2010.

19. Karner C, Chong J and Poole P: Tiotropium versus placebo for chronic obstructive pulmonary disease. Cochrane Database Syst Rev: CD009285, 2012.
20. Vogelmeier C, Hederer B, Glaab T, Schmidt $H$, Rutten-van Molken MP, Beeh KM, Rabe KF and Fabbri LM; POET-COPD Investigators: Tiotropium versus salmeterol for the prevention of exacerbations of COPD. N Engl J Med 364: 1093-1103, 2011

21. Ye Q, Zhang LB, Fan RM, Li JM, Hao Q and Zhao LY: Curative effect of the combination of Symbicort Turbuhaler and Tiotropium Bromide in the treatment of severe stable chronic obstructive pulmonary disease patients. Zhong Hua Fei Bu Ji Bing Za Zhi: Dian Zi Ban 7: 45-48, 2014 (In Chinese).

22. Cazzola M and Molimard M: The scientific rationale for combining long-acting beta2-agonists and muscarinic antagonists in COPD. Pulm Pharmacol Ther 23: 257-267, 2010.

23. Peters SP: Tiotropium bromide triple combination therapy improves lung function and decreases asthma exacerbations. Evid Based Med 18: 179, 2013.

24. Nielsen R, Kankaanranta H, Bjermer L, Lange P, Arnetorp S, Hedegaard M, Stenling A and Mittmann N: Cost effectiveness of adding budesonide/formoterol to tiotropium in COPD in four Nordic countries. Respir Med 107: 1709-1721, 2013.

25. Tricco AC, Strifler L, Veroniki AA, Yazdi F, Khan PA, Scott A, Ng C, Antony J, Mrklas K, D'Souza J, et al: Comparative safety and effectiveness of long-acting inhaled agents for treating chronic obstructive pulmonary disease: A systematic review and network meta-analysis. BMJ Open 5: e009183, 2015.

26. Dal Negro RW and Celli BR: Patient related Outcomes-BODE (PRO-BODE): A composite index incorporating health utilization resources predicts mortality and economic cost of COPD in real life. Respir Med 131: 175-178, 2017.

27. Li HF, Leng J and Huang W: Observation of curative effect in group C, D COPD pateints treated by inhalation of tiotropium bromide combined with budesonide/formoterol. J Kunming Med Univ 35: 62-65, 2014

28. Lee SD, Xie CM, Yunus F, Itoh Y, Ling X, Yu WC and Kiatboonsri S: Efficacy and tolerability of budesonide/formoterol added to tiotropium compared with tiotropium alone in patients with severe or very severe COPD: A randomized, multicentre study in East Asia. Respirology 21: 119-127, 2016.

29. Zhang Q, Wang $M$ and Du CJ: Observation of curative effect in pateints with COPD Complicated with chronic respiratory failure treated by budesonide/formoterol combined with tiotropium bromide. Chin Health Stand Manag 6: 108-110, 2015.

30. Aaron SD, Vandemheen KL, Fergusson D, Maltais F, Bourbeau J, Goldstein R, Balter M, O'Donnell D, McIvor A, Sharma S, et al: Tiotropium in combination with placebo, salmeterol, or fluticasone-salmeterol for treatment of chronic obstructive pulmonary disease: A randomized trial. Ann Intern Med 146: 545-555, 2007.

(i) $\Theta$ This work is licensed under a Creative Commons Attribution-NonCommercial-NoDerivatives 4.0 International (CC BY-NC-ND 4.0) License. 